Ciencia y Educación, Vol. 5, No. 3, septiembre-diciembre, 2021

ISSN (impreso): 2613-8794•ISSN (en línea): 2613-8808

DOI: https://doi.org/10.22206/cyed.2021.v5i3.pp97-116

\title{
Desafíos de la enseñanza de las Ciencias Sociales y Humanas en República Dominicana
}

\author{
Challenges of teaching social sciences in the \\ Dominican Republic
}

\author{
Óscar Gallo a ORCID: 0000-0002-7567-2464 \\ Ana Feliz ${ }^{b}$ ORCID: 0000-0003-3713-1779 \\ María Montero ${ }^{\mathrm{C}}$ ORCID. 0000-0001-5568-2473
}

Recibido: 23/03/2021・Aprobado: 7/06/2021

Cómo citar: Gallo, Óscar, Féliz, A., \& Montero, M. (2021). Desafíos de la enseñanza de las Ciencias Sociales y Humanas en República Dominicana. Ciencia y Educación, 5(3), 97-116. Doi: https://doi.org/10.22206/cyed.2021.v5i3.pp97-116

\section{Resumen}

El objetivo de la investigación con enfoque cualitativo es reflexionar críticamente sobre la enseñanza de las ciencias sociales en las universidades del país y especialmente en la formación de los docentes de educación superior, en un contexto de advenimiento de la Cuarta Revolución Industrial y las transformaciones de la profesión docente en el siglo XXI. Para su realización se entrevistaron y consultaron mediante un formulario con preguntas abiertas y cerradas a 44 docentes de Ciencias Sociales del nivel universitario. Se concluye que para los docentes dominicanos el desafío fundamental de la enseñanza de las Ciencias Sociales y Humanas es el fortalecimiento de la identidad dominicana, la ciudadanía y la democracia, mientras que la mayoría considera que las transformaciones tecnológicas o el impacto de la Cuarta Revolución Industrial en el ámbito educativo son menos significativas.

Palabras clave: Ciencias Sociales y Humanas, educación, docencia, TIC, República Dominicana.

\begin{abstract}
The objective of the research with a qualitative approach is to critically reflect on the teaching of social sciences in the country's universities and especially in the training of higher education teachers, in a context of the advent of the Fourth Industrial Revolution and the transformations of the teaching profession in the 21 st century. To carry it out, 44 university-level Social Sciences teachers were interviewed and consulted using a form with open and closed questions. It is concluded that for Dominican teachers the fundamental challenge of teaching Social and Human Sciences is the strengthening of Dominican identity, citizenship and democracy, while the majority consider that technological transformations or the impact of the Fourth Industrial Revolution in the educational field are less significant.
\end{abstract}

Keywords: Social and Human Sciences, education, teaching, TIC, Dominican Republic.

\footnotetext{
a Instituto Superior de Formación Docente Salomé Ureña (ISFODOSU). Santo Domingo, República Dominicana. Correo-e: oscar.gallo@isfodosu.edu.do

b Instituto Superior de Formación Docente Salomé Ureña (ISFODOSU). Correo-e: ana.feliz@isfodosu.edu.do

c Instituto Superior de Formación Docente Salomé Ureña (ISFODOSU). Correo-e: maria.montero@isfodosu.edu.do
} 


\section{Introducción}

Tanto la Organización Internacional del Trabajo (OIT) (Ryder, 2017) como el Foro Económico Mundial (WEF) han lanzado en los dos últimos años una alerta sobre las transformaciones del mundo laboral y educativo en el contexto del advenimiento de la Cuarta Revolución Industrial (CRI) (Schwab, 2016). Por su parte, la Organización de Estados Iberoamericanos para la Educación, la Ciencia y la Cultura (OEI) ha publicado 88 artículos de divulgación científica sobre los desafíos suscitados por la CRI en el contexto educativo. En los análisis de la OIT, el WEF y la OEI se percibe implícita y explícitamente la preocupación por los procesos de formación profesional y los cambios educativos necesarios en un contexto de profundas transformaciones de los modelos productivos y laborales.

De acuerdo con los expertos, la CRI abarca grandes transformaciones en lo físico, biológico y digital. En este sentido, se esperan avances en la inteligencia artificial, la robótica, los materiales y el Internet. Igualmente, se prevé la intervención del genoma o la transformación de la propia humanidad con tecnologías digitales implantadas, tatuajes inteligentes o accesorios en permanente contacto con Internet (Schwab, 2016). Los pronósticos de Klaus M. Schwab, presidente del Foro Económico Mundial, no son ficción. La "revolución" anticipada por los representantes del mundo empresarial no se restringe a los artificios técnicos. El advenimiento de la industria 4.0 combina el aumento de la riqueza de los sectores tecnológicos y financieros con recetas para la precariedad laboral caracterizadas por la flexibilidad, el cambio, la pérdida de los derechos o la exclusión. Dicho de otra forma, el advenimiento de la industria 4.0 agudiza la crisis de las formas de trabajo decente iniciada a nivel global desde los años 1980 (Durand, 2011; Gorz, 1998; Le Goff, 2009) al extenderse a diversos sectores profesionales entre los que se puede destacar el educativo, con sus contratos temporales, y las formas de prestación de servicio enmarcadas en el modelo de economía colaborativa (Iriarte, 2020).
Además de los tópicos anteriores, en los últimos años, los problemas y desafíos de la Cuarta Revolución Industrial ganaron espacio en diferentes países del mundo, como se puede observar en el portal de Google Trends que mide el interés global por un tema específico en un período de tiempo determinado. De Norte a Sur se debaten diversas facetas éticas de la tecnología, al paso que se critican aquí, allá y acullá el papel de las compañías de tecnología, los cambios suscitados por los avances de la inteligencia artificial, los riesgos del big data, la intromisión de los algoritmos en la democracia, las redes sociales y su relación con la salud mental de los jóvenes o el monopolio de las grandes empresas de tecnología como Amazon, Google, Facebook o Microsoft. De modo que estamos ante un problema global que afecta las esferas pública y privada.

Los efectos de la CRI parecen ser menos visibles en el ámbito educativo; no obstante, la omnipresencia digital, acelerada por el COVID-19, es un hecho que obliga a repensar los caminos que debe transitar la educación del siglo XXI. Acorde con lo anterior, el propósito de este artículo es comprender los desafíos temáticos percibidos por los docentes dominicanos de Ciencias Sociales y Humanas (CSH) a la luz del cambio tecnológico y las dinámicas sociales locales y globales del presente. Responder a esa cuestión implica reflexionar sobre las dinámicas de la educación y los desafíos de la profesión de los docentes en el siglo XXI, porque no se trata únicamente del uso de las Tecnologías de la Información y la Comunicación (TIC) en el aula. Pensar la enseñanza de las CSH es también ahondar en la forma como esta puede contribuir a la construcción de una sociedad donde los individuos sean realmente personas (Gurdián, 2015). La racionalidad instrumental no debe conducir a que docentes y estudiantes fenezcan ante los espejismos de la tecnología en la coyuntura actual.

\section{Marco teórico}

Durante los últimos años ha crecido notablemente la bibliografía sobre las relaciones entre la Cuarta Revolución Industrial y las transformaciones del 
trabajo. De dos artículos académicos en el año 2016, se pasó a 56 y 27 en el año 2020, según Scopus y Web of Sciences, respectivamente. Sin duda, el libro de Klaus M. Schwab influyó en la emergencia del tema y los temores y las esperanzas acumulados desde ese momento explican el auge en el año 2020. Azar más que causalidad parece ser la razón por la cual varios de esos artículos fueron publicados en medio de la crisis sanitaria global, aunque no se puede descartar que muchos fueran inspirados en la pandemia. En general, la bibliografía analiza los cambios en el mercado de trabajo, el impacto de la automatización, los desafíos del cambio tecnológico, las expectativas de desarrollo económico, la innovación y el emprendimiento. El análisis de estas facetas y otras muestran que no hay consenso acerca del futuro del trabajo (Rubbi et al., 2020; Vila De Prado, 2019).

Un fenómeno cronológico similar ocurre cuando se busca en las mismas bases de datos información sobre la expresión "Fourth Industrial Revolution AND education”. En la primera de ellas se registran 483 resultados, de los cuales 344 se publicaron en los años 2019 y 2020. En la segunda, se reportan 178 artículos, 43 de 2019 y 84 de 2020. Dejando a un lado los artículos de las áreas de ingeniería, ciencias de la computación, administración y matemáticas, aproximadamente el $25 \%$ corresponde al campo educativo. Una mirada detenida permite concluir: primero, que en su mayoría abordan la cuestión de las transformaciones digitales en educación junto con los desafíos para la enseñanza y el aprendizaje de competencias profesionales en instituciones universitarias y en campos como la ingeniería y las matemáticas y en función o armonía con la industria 4.0; segundo, se promueven estrategias de aprendizaje activo, aprendizaje flexible, desarrollo de aulas inteligentes, ecosistemas dinámicos, aula invertida, transdisciplinariedad y multidisciplinariedad.

En contraste con la falta de consenso de los artículos que analizan las relaciones entre la CRI y las transformaciones del mundo del trabajo, no hay miradas críticas y parece predominar un optimismo generalizado acerca del potencial de las transformaciones digitales en educación y, a su vez, su poten- cial para el desarrollo de las competencias necesarias para los futuros profesionales. Esta tendencia puede dar la falsa impresión de que la CRI es un problema estrictamente industrial, pero en el ańo 2025 aproximadamente 140 millones de empleos serán ocupados por "empleados informáticos" y las áreas de la física-matemática y las profesiones técnicas tendrán alta acogida, al mismo tiempo que se encogerán las posibilidades para administradores, abogados y docentes (Rubbi et al., 2020; Vila De Prado, 2019).

En vista de la ausencia de una bibliografía que aborde directamente la enseñanza de las ciencias sociales en el contexto del advenimiento de la Cuarta Revolución Industrial, cabe preguntarse por los aportes a la reflexión sobre enseñanza de las $\mathrm{CSH}$ en contextos de crisis o de cambio. En concreto, qué se ha escrito sobre la enseñanza y la didáctica de las CSH en el siglo XXI.

Se localizaron 174 artículos en las bases de datos mencionadas. La bibliografía disponible se enfoca en los desafíos de la enseñanza de la Historia y la Geografía, principalmente en primaria y secundaria; en este horizonte se plantean al menos dos ejes: en el primero se argumenta la necesidad de la enseñanza de estas disciplinas (Arias, 2015, 2017; Prats, 2006); en el segundo, se evalúan las estrategias, las metodologías y los recursos disponibles en la actualidad (Arancibia \& Badia, 2013; Avelas, 2015; Espinoza \& Mora, 2015; Fuertes, 2015).

Se destaca igualmente la literatura orientada a reflexionar sobre la importancia de formar docentes en $\mathrm{CSH}$, la relevancia de estas disciplinas en la educación por competencias y la formación de ciudadanos críticos para el siglo XXI (Barbosa \& Soares, 2017; Guzmán, 2017; Toledo et al., 2015). En la misma línea merecen ser destacados los aportes de las CSH al fortalecimiento de la democracia mediante la investigación y la enseñanza de la memoria histórica, la salvaguarda del patrimonio y el reconocimiento de los movimientos civiles y sociales (Aponte et al., 2014; Ishihara-Brito \& Rodríguez, 2012; Pemjean, 2007). 
Cerca del segundo eje se encuentran las reflexiones sobre el papel de las CSH en la formación de los estudiantes provenientes de otros campos del saber (Guridi \& Arriassecq, 2004), al igual que la importancia de difundir el pensamiento complejo (Cardozo, 2011). Un aspecto transversal a esta literatura es la incorporación de herramientas tecnológicas para el desarrollo de las competencias promovidas por la $\mathrm{CSH}$, tales como el pensamiento crítico y las competencias socioculturales o la inclusión y la diversidad (Cozar et al., 2015; Rakhimova et al., 2017; Weiner, 2015). Cabe anotar que la emergencia de críticas al uso de TIC puede redundar en propuestas consistentes sobre su uso, "pues hasta ahora se ha instalado el imaginario que le otorga poderes a las TIC sobre el aprendizaje" (Jaramillo \& Ruiz, 2009, p. 1) y, en consecuencia, las reflexiones acerca de las TIC han sido muy importantes, pero aún insuficientes para cuestiones esenciales como la sobreabundancia de información falsa en Internet y su uso indiscriminado por docentes y estudiantes, como observa recientemente Sam Wineburg (2018).

En efecto, Mario Carretero y Diego Sobrino López afirman en la introducción de un reciente monográfico sobre Fake News y pensamiento crítico: "mientras que hace algunas décadas el gran desafío de la educación era el acceso a la información, hoy día esa cuestión se ha convertido en cómo generar y enseñar en el uso de herramientas para seleccionar dicha información" (Carretero \& Sobrino, 2020). Previamente, el mismo Carretero había destacado que la proliferación de noticias falsas no era una novedad, pero sí se agrava con los medios digitales y el alarmante papel de algunos países en la difusión de narrativas que fomentan discursos de odio (Carretero, 2019). De ahí, observa Carretero basado en los trabajos de Sam Wineburg: "la urgente necesidad de una "alfabetización de la población escolar y la ciudadanía en el uso de materiales y fuentes digitales que cumplan con el desarrollo de un pensamiento crítico" (Carretero, 2019, p. 57).

Más allá de los debates propuestos por la literatura mencionada, se localizan las investigaciones en las cuales se reflexiona sobre los retos de la didáctica de las $\mathrm{CSH}$ o los procesos psicopedagógicos asociados a la enseñanza-aprendizaje de esta disciplina (Carretero \& Limón, 1993; Ríos \& Ramos, 2011; Rodríguez \& Acosta, 2007). En esta perspectiva pueden incluirse las críticas acerca de los libros escolares (Cerón, 2011; Soaje-de Elias, 2012), el enfoque curricular (Cabeza, 2012) o las perspectivas y experiencias docentes (Bulcourf, 2008; Migueles et al., 2011; Moreno-Fernández, 2018; Solórzano \& Valverde, 2008).

En República Dominicana, sobre la enseñanza de la Historia y de las Ciencias Sociales, se destacan las reflexiones sobre la última reforma curricular. En particular, las investigaciones realizadas indican que el área de sociales ha sido la menos impactada por los cambios mundiales en lo que refiere al desarrollo curricular y las prácticas pedagógicas e investigativas. Por otra parte, González (2019), centrándose en análisis de libros de texto escolar de Ciencias Sociales, resalta en ambos trabajos el carácter tradicional y memorístico de la enseñanza de la historia escolar y los pocos avances en la práctica, a pesar de las modificaciones de los programas curriculares. La autora cuestiona la historia oficial instaurada en la política educativa y los textos escolares por las perspectivas racistas, ahistóricas y machistas. En este sentido, señala que los programas responden a concepciones pedagógicas modernas, mientras que el enfoque en los libros de texto reivindica una historia oficial cargada de mitos sobre los orígenes, con una escasa alusión a la historia de las mujeres y un racismo expresado en el prejuicio cultural y la discriminación de expresiones religiosas o tradiciones ancladas en la esclavitud.

En cuanto a los desafíos de la enseñanza de las Ciencias Sociales hoy, la bibliografía dominicana coincide en la importancia de fortalecer la formación docente fundamentada en una mejor formación disciplinar y mayores experiencias de investigación interdisciplinar. En esta misma línea, señalan que se destaca "la importancia del conocimiento epistemológico de las Ciencias Sociales que define las rutas de la enseñanza” (Aguilera, 2017). A manera de síntesis, los expertos señalan que es necesario "una política permanente de fortalecimiento y perfeccionamiento docente que tome como referencia las nuevas corrientes en 
el campo de la pedagogía y, una revisión periódica de los contenidos de los programas y de la didáctica para desarrollar el proceso de enseñanza aprendizaje" (Durán, 2019; Rosario, 2019).

Aunque existen algunos trabajos que abordan tangencialmente la cuestión de las CSH en el siglo XXI, la conclusión después de revisar la literatura es que no se ha realizado o no se ha publicado un trabajo similar en República Dominicana y son pocos los aportes al tema en la región (Arias, 2017; Muñoz \& Martínez, 2015; Pantoja, 2017). En una frase, el artículo constituye un aporte a la reflexión sobre el lugar que las CSH deben tener en la formación del docente dominicano del siglo XXI a la luz de los cambios suscitados por la CRI. Es en momentos de encrucijadas sociales, políticas y éticas donde el papel del pensamiento sobre lo humano se torna imprescindible.

\section{Metodología}

El objetivo de esta investigación con enfoque cualitativo es reflexionar críticamente sobre la enseńanza de las ciencias sociales en las universidades del país y especialmente en la formación docente de educación superior, en un contexto de advenimiento de la Cuarta Revolución Industrial y las transformaciones de la profesión docente en el siglo XXI. Dicho de otra manera, nos interesa saber cuáles eran los desafíos de la enseñanza de las ciencias sociales en República Dominicana en un contexto de transformaciones sociales y económicas suscitadas por la última revolución industrial.

En el diseño de investigación se incorporaron principios subyacentes a dos tipos de investigación cualitativa: la teoría fundamentada y el enfoque fenomenológico. Es por esto que, para alcanzar el propósito de la investigación, se realizaron principalmente entrevistas semiestructuradas a profundidad a docentes dominicanos de Ciencias Sociales, pertenecientes a universidades públicas y privadas de Santiago, San Pedro de Macorís, Santo Domingo y San Juan de la Maguana. Las entrevistas se realizaron principalmente en el lugar de trabajo del participante y en espacios donde este estaba cómodo sin la presencia de personas diferentes a las del equipo de investigación.

Por el enfoque y tipo de investigación descrito, la cantidad de entrevistas realizadas no obedeció a fórmulas de probabilidad como en el muestreo cuantitativo, sino al objetivo de la investigación, la capacidad operativa de los investigadores, las posibilidades de comprensión del fenómeno, la naturaleza del análisis propuesto, tal como sugieren diversos expertos en la materia (Miles et al., 2014). En una frase, se trató de un muestreo de selección gradual de expertos según el juicio de los investigadores y considerando el punto de saturación teórica. Así, el trabajo de campo se realizó entre noviembre del año 2019 y marzo del año 2020; durante este intervalo se realizaron entrevistas y análisis de la información con el fin de identificar un posible punto de saturación o el momento en que debíamos dejar de realizar entrevistas. En este sentido seguimos dos criterios: primero, la sensación de reiteración de los aportes o el agotamiento de la novedad en los argumentos sobre el tema; segundo, el momento de saturación teórica cuando los casos recogidos en las entrevistas aportaban suficiente información para todas las categorías escogidas (Cheah, 2020; Fusch \& Ness, 2015; Saunders et al., 2018).

Como se mencionó antes, para alcanzar el objetivo se utilizó como principal técnica de investigación la entrevista semiestructurada a profundidad. Las entrevistas se complementaron con un formulario de preguntas abiertas implementado porque la pandemia de COVID impidió continuar con el proceso de entrevistas.

Para orientar las entrevistas, en lugar de una guía de preguntas se creó un instrumento que denominamos Representación Pictórica de los Desafíos de la Enseñanza de las Ciencias Sociales en República Dominicana (REPDECS). El instrumento se inspira en la Técnica de Generación de Estructuras (TGE) y las estrategias de análisis mediante redes y mapas mentales de la teoría fundamentada (Flick, 2007). Pero, también se inspiró en un método denominado: Representación Pictórica de la Enfermedad y 
el Auto Cuidado (PRISM por sus siglas en inglés) (Büchi \& Sensky, 1999; Sensky \& Büchi, 2016)a .

Al utilizar PRISM, en su adaptación REPDECS, no quisimos analizar las emociones y los sentimientos de los docentes; nuestro objetivo era fundamentalmente crear un medio por el cual los docentes pudieran jerarquizar visualmente lo expresado en sus respuestas y motivar la conversación. En la práctica, el instrumento usado es IPRISM, una aplicación disponible en Android y Itunes, diseñada de acuerdo con el método PRISM. En ella el investigador introduce unas categorías de análisis y el entrevistado establece una jerarquía entre diversas categorías relacionadas con el fenómeno social investigado. Como ya se anotó, en una investigación anterior se realizaron pruebas para evaluar la pertinencia de esta herramienta de representación pictórica en el análisis de fenómenos sociales complejos como la motivación de los trabajadores en las organizaciones (Román-Calderón et al., 2020). La versión adaptada para la comprensión de los desafíos de la enseñanza de las Ciencias Sociales fue previamente presentada a tres investigadores independientes que formularon recomendaciones sobre las categorías de análisis incluidas.

El REPDECS se utilizó como se describe a continuación. La entrevista comienza con una presentación breve de los objetivos de la investigación y las expectativas que se tienen, además de la creación de una ficha con los datos personales, la elaboración de un código alfanumérico de anomización ${ }^{\mathrm{b}}$ y la firma del consentimiento informado. Luego, se presentó a los voluntarios la metodología de la entrevista y el tiempo requerido (máximo 45 minutos). El entrevistado recibe una Tablet con una imagen como la siguiente:

\section{Figura 1}

Captura de pantalla Herramienta de Representación Pictórica de los Desafíos de la Enseñanza de las Ciencias Sociales en República Dominicana

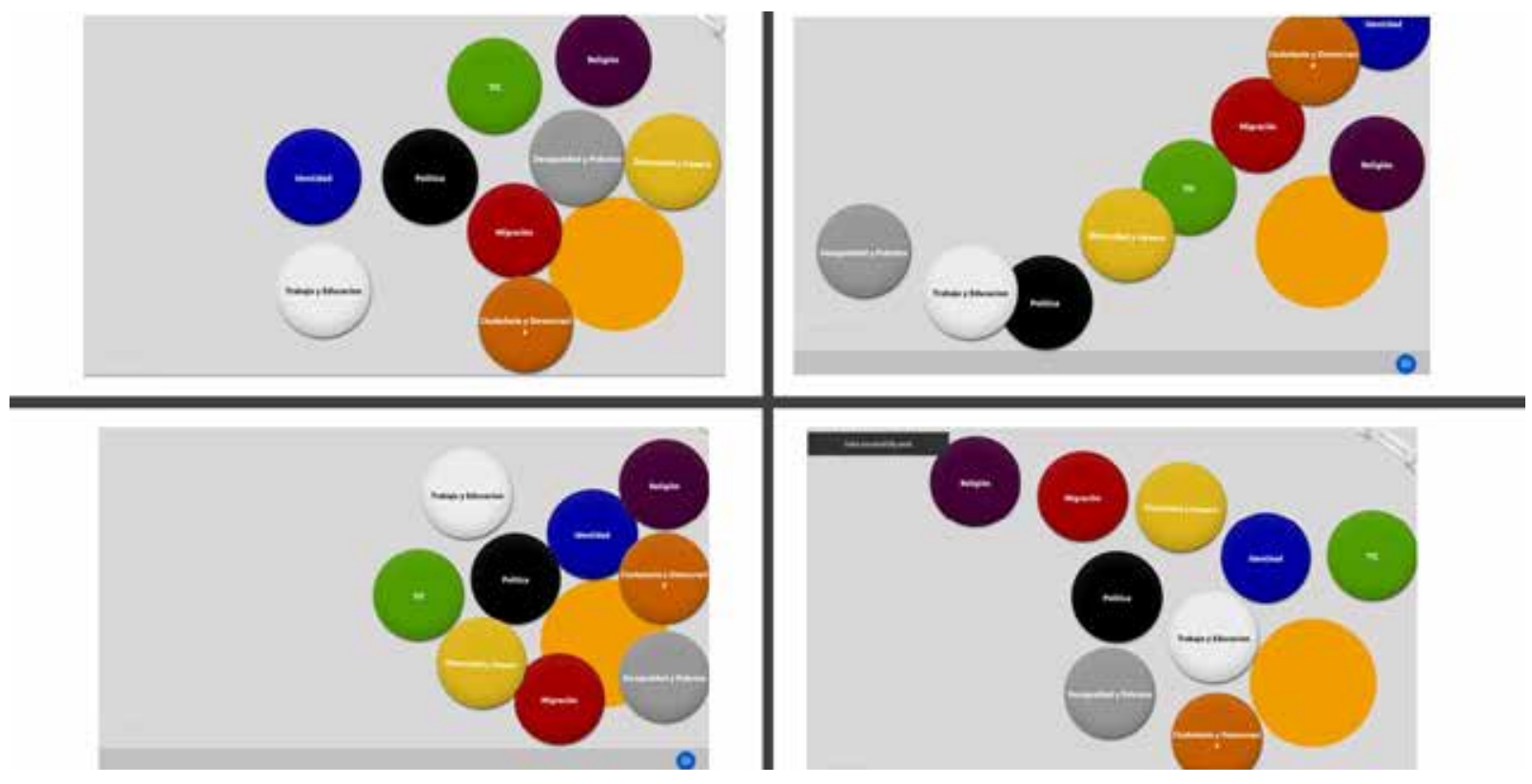

a. Este instrumento, creado por los profesores Stefan Büchi y Tom Sensky de la Universidad de Zürich, observa las relaciones que establecen los pacientes de enfermedades crónicas con ciertos aspectos de la vida cotidiana, las emociones y los sentimientos. No obstante, también se ha usado en otros ámbitos como estrategia para analizar las impresiones de los sujetos frente a una serie de eventos y experiencias en el ámbito laboral (Román-Calderón et al., 2020).

b. Como se verá en la sección de resultados y discusión, las entrevistas se numeraron con el código alfanumérico formando las letras EDP (Entrevista Documento Primario) y un número correspondiente a la localización en la base de datos elaborada en MaxQDA. Por otro lado, los formularios creados para complementar la información obtenida en las entrevistas se nombraron siguiendo la misma lógica. Por ejemplo, FRD que corresponde a Formulario República Dominicana y un número de acuerdo con la clasificación en la base de datos. 
El procedimiento para establecer el sistema de categorías analíticas incluidas en el instrumento implicó la elaboración de una lista global de frecuencia de palabras y, posteriormente, la identificación de las categorías o los conceptos con relevancia heurística; por ejemplo, se encontró que en la literatura analizada las siguientes palabras aparecían frecuentemente: enseñanza, conocimiento, identidad, sociedad, dere- chos, participación, ciudadanía, género, mujeres, política. Finalmente, de ese grupo el equipo de investigación escogió las categorías que se iban a usar en los instrumentos basado tanto en la importancia discursiva como en la lectura de la información recabada. Del proceso anterior y la adaptación al proyecto de investigación y el contexto dominicano obtuvimos las siguientes categorías de análisis (ver Figura 2).

\section{Figura 2}

Categorías incluidas en el instrumento de Representación Pictórica de los Desafios de la Enseñanza de las Ciencias Sociales en República Dominicana

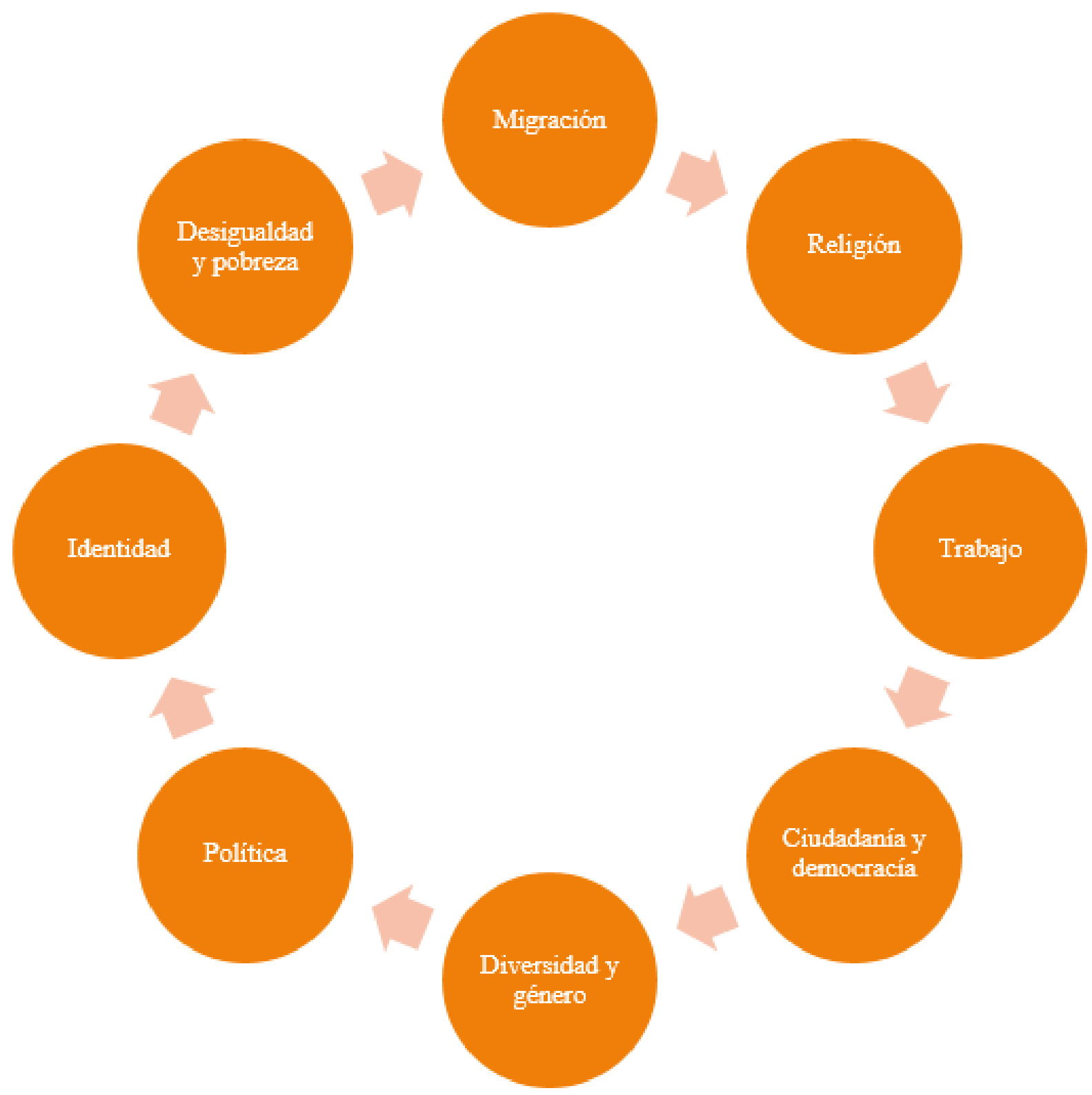


Para complementar la información obtenida en las 21 entrevistas realizadas en la primera fase del proyecto, se compartió un formulario de preguntas abiertas y cerradas a 23 docentes universitarios diferentes de los entrevistados y pertenecientes a las universidades ya mencionadas. El formulario siguió la misma lógica de las entrevistas y constituye un método alternativo de recuperación de las experiencias de cambio y transformación en la coyuntura actual, pero no un muestreo estadístico. Cabe anotar que este cambio en el instrumento que permitió enfrentar una contingencia del COVID-19 no implica un problema metodológico. Como afirman los expertos, en la investigación cualitativa es necesario un descarado eclecticismo y es precisamente esa naturaleza ecléctica, fluida, flexible e innovadora la que enriquece tanto el diseño como el análisis y los hallazgos (Miles et al., 2014).

Finalmente, con respecto a la estrategia analítica para las entrevistas e información obtenida en los formularios utilizamos MaxQDA 2020. La utilidad de este tipo de herramientas radica en la posibilidad de organizar, integrar, ver y presentar la información a través de redes. Su uso, especialmente interesante cuando se busca obtener información de entrevistas, implica un análisis sistemático consistente en preparación de los datos, codificación (abstracción, generalización, síntesis y comparación, código integración), delimitación teórica, presentación de datos utilizando mapas conceptuales o redes, y la composición y verificación de conclusiones (Miles et al., 2014).

Dado que toda la información obtenida es fundamentalmente cualitativa se utilizó la misma estrategia de análisis tanto para las entrevistas como para las respuestas al formulario de preguntas abiertas y cerradas. De esta manera, las respuestas al formulario se exportaron a Excel y posteriormente importaron a MaxQDA 2020. Las entrevistas, luego de transcritas, fueron igualmente incorporadas al mismo software. En ese punto, se inició un proceso de análisis sistemático de la información consistente en creación de nubes de palabras, listas de frecuencias, la lectura y búsqueda de incidentes, fenómenos, temas, palabras $\mathrm{y}$ frases que representaran similitud y diferencias. El procedimiento de codificación inductiva y deductiva se combinó con codificación selectiva o abductiva basada en la evidencia de la literatura previamente consultada. El método descrito anteriormente incluye ciertos principios subyacentes de la teoría fundamentada, el enfoque fenomenológico y el análisis de contenido (Miles et al., 2014, p. 9).

\section{Resultados}

A la pregunta sobre los desafíos de la enseñanza de las CSH en el siglo XXI, los entrevistados respondieron REPDECS, como se observa en la Figura 3.

\section{Figura 3}

Representación Pictórica de los Desafios de la Enseñanza de las Ciencias Sociales en República Dominicana (Distancia promedio)

\section{Distancia Promedio}

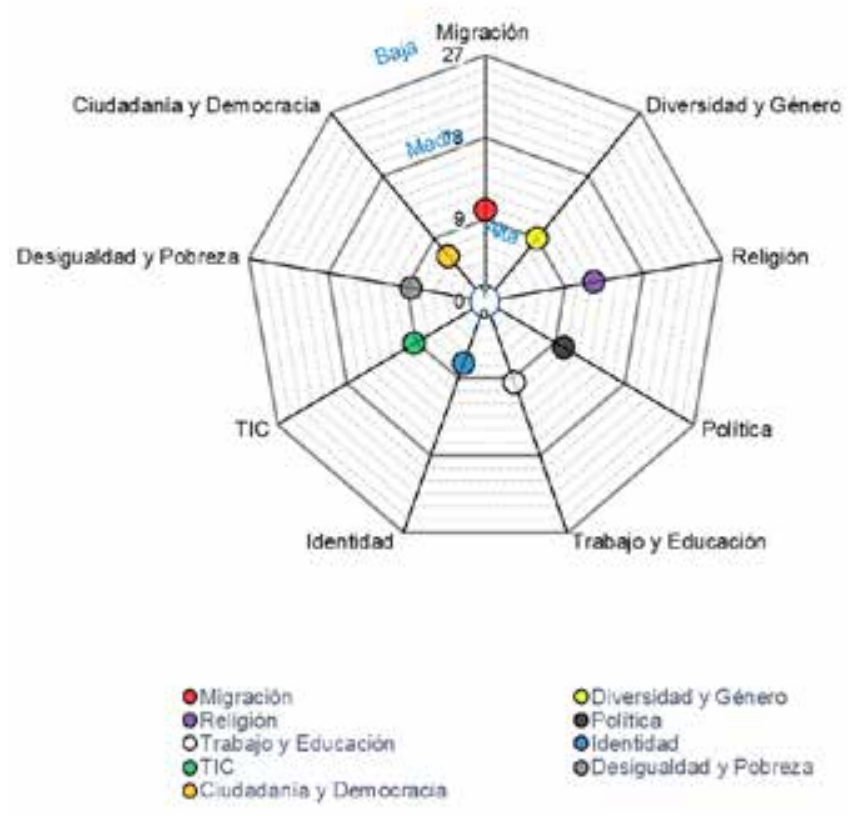

Nota: la tabla es elaboración propia basada en la REPDECS.

El promedio de la distancia entre la categoría y el círculo amarillo insinúa que todos los aspectos son pertinentes en la enseńanza de las CSH en el siglo XXI; 
de hecho, el promedio muestra que ningún factor es considerado de relevancia baja entre los entrevistados y únicamente Identidad y Ciudadanía tendrían una relevancia alta más explícita. De hecho, los tópicos de Diversidad y Género, Desigualdad y Pobreza y TIC aparecen en un rango de interés medio-alto o en límites entre ambos niveles, según lo muestra la gráfica. Esto evidencia cómo los procesos de transformación digital secundarios en el momento de las entrevistas pueden adquirir un rango elevado de importancia si se presentan cambios en el contexto.

Ahora bien, los resultados desagregados (Figura 4) insinúan una tendencia diferente que se constata en términos discursivos, como veremos más adelante.

\section{Figura 4}

Representación Pictórica de los Desafios de la Enseñanza de las Ciencias Sociales en República Dominicana (Distancia desagrada)

\section{DISTANCIA DESAGREGADA}

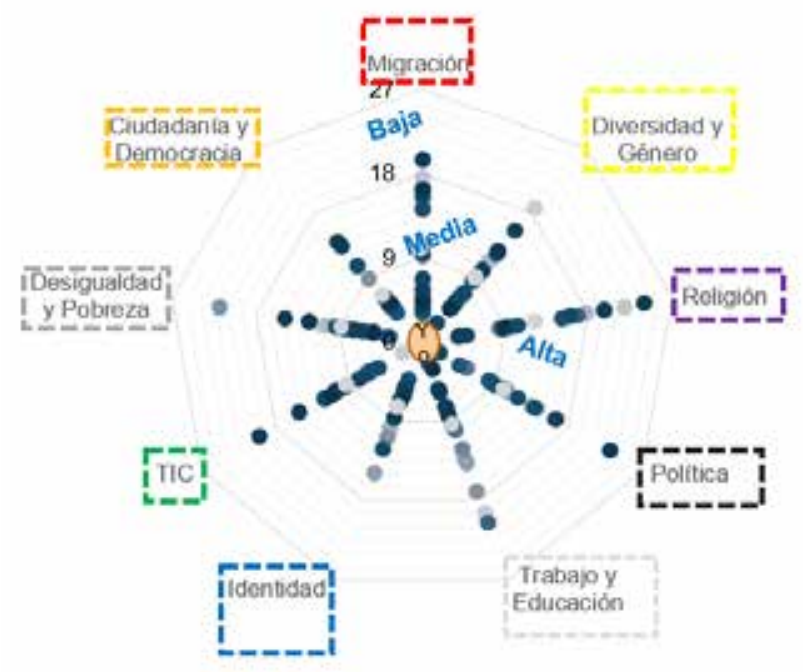

Nota: la tabla es elaboración propia basada en la REPDECS.

De la distribución desagregada se puede concluir que las categorías Religión y Trabajo son pictóricamente menos significativas, mientras que los círculos se localizaron más cerca del punto amarillo en el caso de Ciudadanía y Democracia e Identidad. La localización de la política refuerza la importancia del primer par de conceptos. Es interesante constatar que el $52.17 \%$ de los docentes que recibieron el formulario virtual de preguntas se siente poco satisfecho con la forma como es abordado el tema de la identidad en los programas de CSH del país, mientras que el 26.09\% está moderadamente insatisfecho. Con respecto al tema de la ciudadanía, el $54.55 \%$ se siente moderadamente insatisfecho, el $22.73 \%$ está poco satisfecho y el $9.9 \%$ se siente definitivamente insatisfecho.

A todos los entrevistados se les preguntó por el grupo de categorías incluidas en el REDPECS; sin embargo, algunos códigos fueron omitidos por los participantes por considerarlos menos significativos para la docencia del siglo XXI; por ejemplo, religión, o porque en su opinión la categoría podía ser subsumida por otras, como es el caso de la política. Como se puede observar en la gráfica de segmentos codificados, las categorías de Identidad, Diversidad y Ciudadanía ocuparon un lugar central en la conversación, seguido de Religión, Migración y Política. Mientras que TIC, Trabajo y Desigualdad y Pobreza ocuparon lugares menos significativos discursivamente:

\section{Figura 5}

Porcentaje de segmentos codificados según código

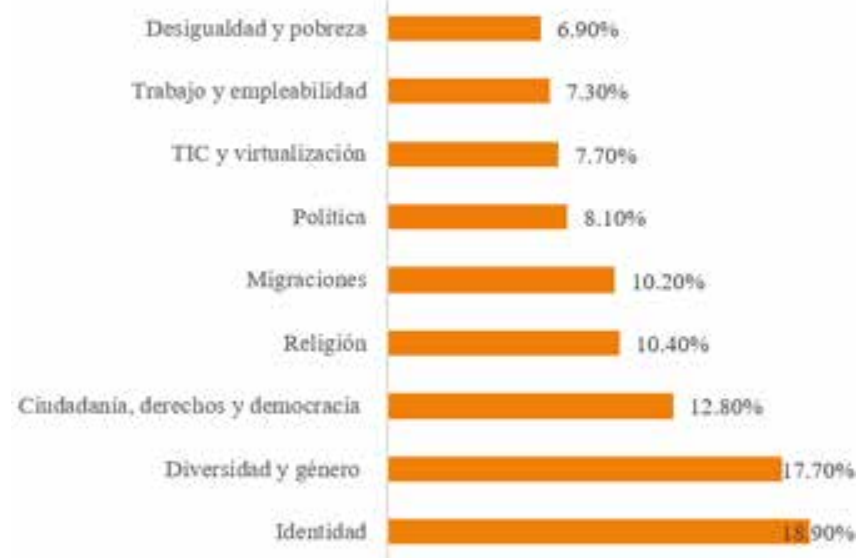

Nota: la tabla es elaboración propia con datos obtenidos de MaxQDA 2020. 
El análisis sistemático de la información nos permitió también confirmar algunas tendencias, así como identificar otros patrones. Normalmente, una vez codificada la información con cualquier QAQDAS se utilizan las herramientas de análisis de intersección de códigos en un segmento, proximidad de códigos en el mismo documento y ocurrencia de códigos en el mismo documento. En el caso concreto, la ocurrencia no es tan útil porque los entrevistados debían hablar de todos los códigos, de modo que la intersección y proximidad ofrece pistas interesantes sobre la percepción que los docentes tienen sobre las cuestiones planteadas. Así, de la intersección de códigos en un segmento, se deduce que los entrevistados a menudo relacionan el uso de las TIC con una formación para el trabajo o la empleabilidad; del mismo modo, existe una fuerte correlación entre migraciones e identidad. A su vez, el tema de las migraciones se relaciona en menor medida con la ciudadanía y la democracia, y la diversidad y el género. Finalmente, religión y política aparecen con frecuencia en un mismo contexto argumentativo (Figura 5).

\section{Figura 6}

Mapa de códigos y coocurrencias
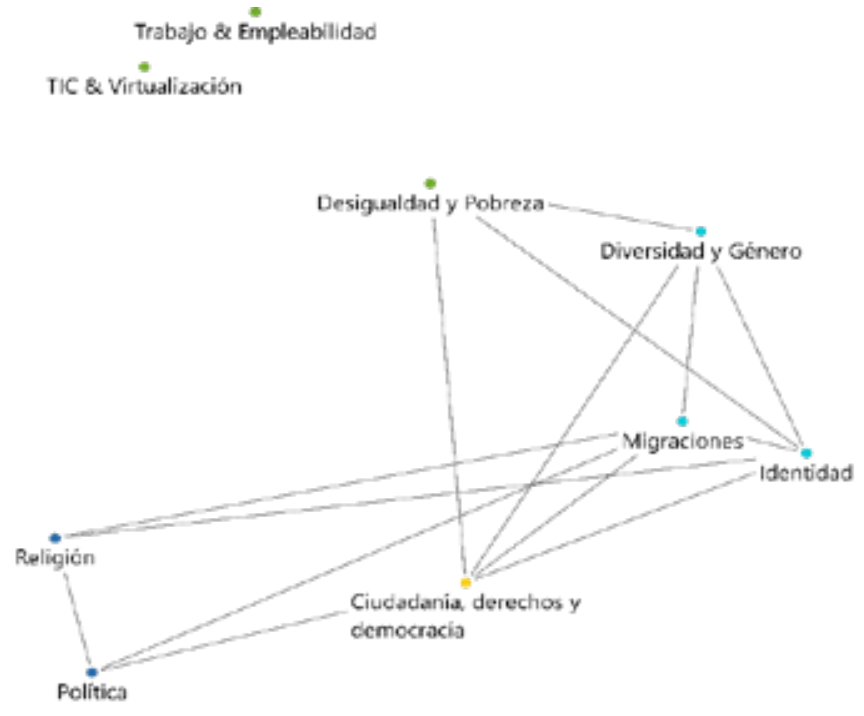

Nota: la tabla es elaboración propia con MaxQDA 2020.
Si la intersección se refiere a las veces en que el entrevistado juntó ambas categorías en un mismo argumento, la proximidad de códigos en el mismo documento muestra cómo los temas se sucedieron en la conversación. En este caso la tríada migraciones, identidad y ciudadanía es reafirmada por su contigüidad, al igual que la dupla religión y política. No obstante, a diferencia de la interseccionalidad anterior entre trabajo y TIC, la distancia sugiere una contigüidad discursiva no significativa al paso que emerge la relación entre las tecnologías de la información y la desigualdad y la pobreza, y de esta última con diversidad y género.

\section{Figura 7 \\ Mapa de códigos y proximidad discursiva}

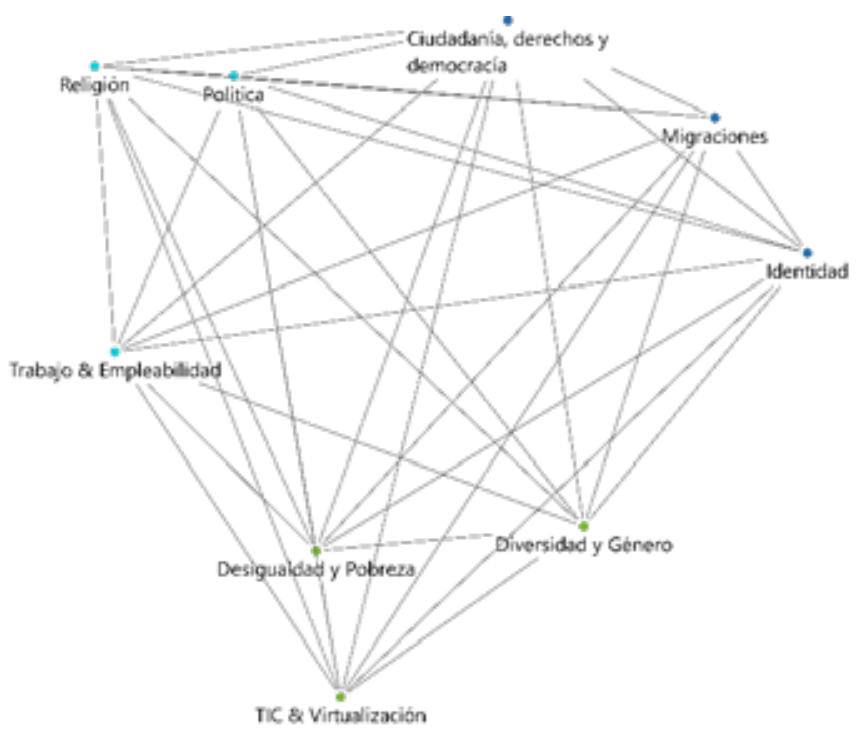

Nota: la tabla es elaboración propia con MaxQDA 2020.

En resumen, de las tendencias presentadas podemos destacar algunos aspectos antes de pasar a discutirlos. Aunque la distribución pictórica agregada insinúa que ninguno de los aspectos está por encima de otros y todos son esenciales en la formación de los futuros docentes de CSH, al desagregar y analizar sistemáticamente la información de las entrevistas observamos que los temas esenciales son identidad, democracia y ciudadanía, diversidad y género. Por otro 
lado, se destacan en las entrevistas los argumentos en contra de la inserción de temas como religión y política en el marco de los procesos de formación, consecuente con la distancia expresada REDPECS. Así mismo, en lo que respecta a las tecnologías de la información y la comunicación, estas ocupan un lugar distante en la valoración de los docentes de Ciencias Sociales.

\section{Conclusiones y discusiones}

Como hemos visto hasta este punto, el tema que más preocupa pictórica y discursivamente a los docentes de Ciencias Sociales de República Dominicana es el de la identidad; sin embargo, no existe univocidad conceptual y, por el contrario, la identidad es entendida de múltiples formas; por lo mismo, varían el horizonte del problema y el papel de las Ciencias Sociales en los procesos de formación de los futuros docentes. Pese a la diversidad de argumentos, se pueden identificar dos tendencias analíticas: en primer lugar, un grupo de docentes que reivindica la recuperación de los símbolos patrios, la historia y la defensa de la dominicanidad y lo nacional como estrategia para contrarrestar los efectos desastrosos de la transculturación y la pérdida de valores; este punto de vista remite a sentimientos patrios que están por encima de cualquier religión o color de piel; las Ciencias Sociales tienen en este enfoque una función de formación y legitimación del Estado-Nación. Como anotamos en el apartado anterior, la identidad tiene una correlación fuerte con la migración. Para los entrevistados que representan este grupo, la identidad dominicana se construye fundamentalmente en relación con la inmigración y los problemas sociales que suscitan el flujo continuo de personas; por lo tanto, las Ciencias Sociales deben servir para fortalecer el sentimiento de pertenencia a la nación dominicana (EDP9)c.

En contraste con este enfoque, algunos docentes se manifiestan en contra de una formación inspirada en una visión de la identidad nacional o de la instrumentalización de las Ciencias Sociales; en concreto, el uso de la historia como herramienta de adoctrinamiento y la utilización de la misma disciplina para tensionar las conflictivas relaciones con los inmigrantes. Los representantes de este abordaje presentan múltiples versiones de la historia en sus clases y defienden una absoluta neutralidad y objetividad cercana, por momentos, a una suerte de asepsia discursiva; segundo, reconocen la pluralidad de la categoría y advierten que es imposible pensarla sin relación con otras, como diversidad sexual y clase social; finalmente, insisten en la importancia de resignificar la identidad dominicana y avanzar en el estudio del tema para romper con las perspectivas más tradicionalistas ancladas en la tradición colonialista e hispánica que oculta las herencias africanas de la sociedad dominicana.

Al igual que en otros países de la región, la reflexión crítica sobre la identidad se construye en contradicción, por un lado, con las estructuras de sentimientos o las ideologías identitarias promovidas por la dictadura o los populismos; por el otro, reforzadas a través de los diferentes discursos en los que se participa (Pink $\&$ Filella Roc, 2019). Desde este punto de vista es posible entrever en las palabras de algunos de los entrevistados la idea de que la identidad es performativa, por lo tanto, no existe una naturaleza estable o permanente de esta (Atienza \& Van Dijk, 2010, p. 71).

Cabe destacar que, en ambas versiones, la identidad es condición de posibilidad para la ciudadanía; dicho de otra manera, es el punto de partida para la defensa de un régimen democrático y la participación en la política o el empoderamiento social. Desde este punto de vista, los entrevistados perciben que los jóvenes dominicanos han comenzado a explorar y aceptar otras formas de identidad, cuyas manifestaciones cotidianas son signos de ruptura y resistencia. Pero los actos de independencia de espíritu no se limitan al cabello o la ropa, también fracturan con su crítica la imagen positiva que normalmente cubre la identidad, asumiendo sus problemas y horrores, y la importancia de fortalecer "esa peculiar forma de identidad que es la ciudadanía", como afirma Adela Cortina (Blanco, 2016, pp. 178-179).

c Código alfanúmero creado para garantizar el anonimato de los participantes. Ver nota al pie anterior. 
Podemos interpretar que la cuestión de la identidad está referida en los docentes entrevistados a la reafirmación de la identidad nacional frente a procesos de globalización y, en menor grado, a las nuevas narrativas identitarias. La aproximación de las identidades nacionales refleja un esencialismo culturalista y un nacionalismo antihaitiano al estilo de las ideas de Balaguer en La isla al revés (1983). La cuestión de la identidad nacional tuvo fuerza en los debates académicos de los años ochenta en el país, cuando desde las universidades el discurso planteó un giro al rasero hispanista de la identidad nacional dominicana que había impuesto la dictadura. Es necesario recordar los trabajos pioneros desde la antropología y la historia en los años setenta, de Dipp (1979) y Franco (1979), entre otros. Y en los ańos ochenta y en los noventa se incorporaron debates y trabajos académicos en torno al prejuicio racial y la identidad que resaltan la participación y los aportes de las culturas populares, como observa la historiadora Ana Féliz (2017). Otros autores se acercan a los debates sobre la interculturalidad más normativa que culturalista y más cercana a una ciudadanía político-normativa (González, 2010; Mella, 2005). Recientemente, la literatura, las artes plásticas y performativas están dando un giro a las narrativas identitarias dominicanas, en una perspectiva más cosmopolita que supera el marco nacional y territorial. Sin embargo, podemos concluir que estos giros no han alcanzado los ámbitos de la formación en Ciencias Sociales y Humanas y la formación docente en general.

La tensión entre ambas visiones se expresa en la crítica al ensimismamiento local, la excesiva exaltación de la historia patria y la poca autocrítica cultural (FRD 3) que, a menudo, conduce a un "abordaje de la identidad que contiene sesgos racistas y desconoce el aporte de los afrodescendientes y los sectores marginados" (FRD10). Como observa uno de los encuestados: "el tema de la identidad, las migraciones, la equidad de género y el racismo siguen siendo temas que dividen la sociedad, aún no existe un nivel de conciencia social al respecto y las críticas que han recibido diferentes sectores por manifestarse en contra del racismo, me confirman que todavía es materia pendiente. El tema de ciudadanía ha cobrado cierto relieve y la religión se ha introyectado después del auge del protestantismo" (FRD 15). Frente a esta situación vista también como uno de los principales problemas de la enseñanza de las Ciencias Sociales en República Dominicana, algunos participantes insisten en la interdisciplinariedad, la conciencia de "la relación con los contextos y entornos sociales y naturales" (ERD 5), el desarrollo de una conciencia y una cultura histórica (FRD 10) y el refuerzo de la noción de pertenencia a una ciudadanía global" (FRD 10; FRD 15).

Con respecto a la ciudadanía y la democracia, los argumentos expresados en el formulario destacan la importancia de abandonar el ensimismamiento local, hacer que la formación ciudadana sea transversal, cualificar la opinión pública y abrir espacios de participación. Así mismo se destacan la crítica a la ideología promovida por los sectores dominantes y, en consecuencia, el desprestigio de algunos temas "neurálgicos en la formación de un sujeto crítico, analítico y participativo" (FRD 18). Respecto a la ideología que afecta los procesos de formación en ciudadanía y democracia, es difícil identificar las anclas conceptuales con la información disponible; no obstante, entre los docentes se observa algunas vertientes: primero, la crítica al "radicalismo" y "una formación en el marco del materialismo dialéctico y materialismo histórico" (FRD 20); segundo, crítica a la defensa de los mitos fundacionales con su fuerte tradición memorística y su precario abordaje de las identidades, las migraciones, el medioambiente y la ciudadanía; esta vertiente normalmente aparece asociada con una escuela dominicana que reproduce la discriminación de género y racial (FRD5). De uno y de otro lado se cuestionan los contenidos curriculares porque no buscan cambios estructurales en las estrategias ni actividades para la formación de una ciudadanía responsable, probablemente por la falta de recursos didácticos apropiados y el desinterés de la sociedad en general (ERD 9); incluso porque en ocasiones los mismos libros de texto reiteran una perspectiva que desconoce o invisibiliza el pasado de esclavitud, colonialidad y violencia (EDP10). 
Los significados relacionados con las categorías de Ciudadanía y Democracia en el análisis de los profesores universitarios participantes son diversos, distintos y distantes. Sin embargo, sintonizan con discursos o marcos de ideas del pasado o del presente. En primer lugar, la ciudadanía y la democracia aparecen como sistema político formal. Algunos docentes relacionaron democracia con libertad de expresión, derecho a elegir, poder popular, que forman parte de la visión formal de la democracia (liberal). Aunque no se refirieron a los procesos históricos dominicanos o a las problemáticas actuales de la democracia dominicana, sí identificaron retos actuales como: "Fortalecer la conciencia ciudadana y de los ciudadanos en favor de una mejor administración de los recursos"; "La democracia es uno de los retos y desafíos dentro del área de ciencias sociales, porque necesitamos formar y desarrollar esas habilidades en los que estamos formando, debido a que necesitamos compromisos como ciudadanos". Así mismo, se destacan las referencias que vinculan ciudadanía y democracia con prerrogativas territoriales de los Estados-nacionales: "para mí tiene cierta afinidad con la política [...] la construcción de las naciones nos da más ciudadanía, aunque nosotros podemos ir a otra nación que no es la nuestra y adquirirla es una ciudadanía que se adquiere por ventaja personal" (EDP8). En otros casos la ciudadanía aparece subordinada a la memoria de un pueblo, al patrimonio y a la conciencia histórica del país.

En segundo lugar, se destaca la democracia en línea sustantiva. En este sentido, los entrevistados plantearon aspectos críticos frente a la democracia formal y resaltaron aspectos de la democracia sustantiva, más allá del voto, como son mayor participación ciudadana o calidad de vida. En este horizonte se puede citar:

...tú puedes hablar de un estado cuando vive en democracia formal y qué tiene de democrático, el voto qué tiene de democrático en cuanto a libertad de información yo diría libertad de no verse perseguido por opinar en público o sea ciertas características de la vida en democracia, pero creo que la democracia real se considera como una democracia a nivel ciudadano, hace falta mayores espacios de participación, de toma de decisiones que creo que no hay en todas las democracias. (EDP11)
En tercer lugar, aparece una visión autoritaria de la ciudadanía. Las expresiones y los significados relativos a una "moral cívica" o con educación cívica se acercan a una visión de ciudadanía de los períodos de las dictaduras de Trujillo y Balaguer, ya que fue una característica que imprimió "valores morales" propios de la tradición autoritaria que veía amenazas (en lo de fuera o en la migración haitiana). Encontramos rastros de estas ideas:

La ciudadanía es un elemento que tenemos que trabajarlo mucho porque hay dominicanos, en el caso nuestro, que no se consideran dominicanos porque quieren adoptar culturas ajenas, foráneas, muchas veces influidas por los medios de comunicación. Pero el verdadero dominicano tiene que empoderarse de su derecho, de donde somos nuestra ciudadanía, para poder luchar por una democracia plena y para poder tener el espacio y el valor como combatir los malos hechos o actos provocados por la política de la migración que tenemos por allá atrás. (EDP8)

Esta visión y relación entre ciudadanía, moral y cívica deja por fuera la cuestión de los derechos de ciudadanía y además no prevé los cambios, las readecuaciones y los giros en los marcos normativos y de comprensión de la relación entre derechos y ciudadanía. Para algunos de los entrevistados: "todavía tenemos mucho por avanzar en una conciencia ciudadana crítica, que la política se trabaje desde la óptica de la ciencia y que nuestro estudiantado, nuestros gestores y colegas entiendan que la política como ciencia es un escenario para nosotros" (EDP1). Al mismo tiempo, "hay dificultad para poder hilar estos temas de forma concatenada. Hay dificultad de mirar interrelaciones. Una mirada transversal. De qué forma la democracia está relacionada con la discusión del modelo económico, de la crisis de la democracia” (EDP13).

Los argumentos sobre ciudadanía, en resumen, reflejan yuxtaposiciones. Pero las aproximaciones apenas prevén reflexiones teóricas que se discuten en las academias y desde las ciencias sociales actualmente. Así, por ejemplo, no se perciben en el discurso referencias a lo local-global de los movimientos sociales y culturales que se desarrollan, en el marco de la sociedad 
red de Castells (2014, 2015) y Castells et al. (2006), o las relaciones de poder y la centralidad de lo político de Rosanvallon (2010); en línea con la Ciudadanía cosmopolita (Appiah et al., 2016; Cortina, 1998); o con relación a la "Democracia compleja" (Innerarity, 2020). De acuerdo con García-Canclini (1992), la ciudadanía no viene dada ya por los referentes tradicionales (territorio, una comunidad de origen, etc.); aunque algunos de los entrevistados avanzan en este sentido, se deben replantear las concepciones y la formación en torno a la ciudadanía.

Por último, lo más importante es lograr que la enseñanza de las Ciencias Sociales impulse debates sobre la diversidad y el género. De acuerdo con varios de los entrevistados, la universidad dominicana y, en concreto las Ciencias Sociales, tienen que hablar de racismo, discriminación, genero, negritud, al igual que de la corrupción, la concentración de la riqueza y la desigualdad social. En este ámbito se destaca igualmente la brecha entre lo que expresa el currículo, vanguardista en muchos aspectos, y la realidad en las aulas. Dicho de otra manera, los docentes entrevistados observan una distancia entre discurso y práctica: "tenemos teoría, pero no hemos hecho la práctica, los programas son bellísimos, pero la práctica poco se ha dado" (EDP6). Todo este panorama se ve agravado por un contexto donde las tradiciones religiosas chocan con las acciones institucionales o la política pública de género. Ninguno de los docentes entrevistados desconoce que República Dominicana tiene, junto con otros países centroamericanos, la tasa más alta de feminicidios de la región, de ahí que todos insistan en la importancia de sensibilizar a los futuros docentes sobre la violencia de género. Como observa una de las entrevistadas:

lo que está ocurriendo con los feminicidios nos evidencia que lo que se está haciendo hasta ahora no es suficiente y que se requiere realmente que las autoridades, pero también personas involucradas a través de representantes de la sociedad civil, ONG y demás también participen en la toma de decisiones o en la discusión que requiere este tema para buscar solución y encontrarle respuestas. (EDP23)
Se trata pues de impulsar un debate y crear una nueva sensibilidad entre los docentes para que una vez en la escuela favorezcan "una identidad positiva, y que valore favorablemente la diversidad de todo tipo y respete otras realidades y visiones del mundo" (Carretero et al., 2015, p. 207).

Más allá de los desafíos con respecto a estos grandes temas, los participantes identifican un conjunto de problemas en el proceso de formación de los futuros docentes de Ciencias Sociales y Humanas. Para comenzar, advierten la frágil formación de los estudiantes de recién ingreso a la universidad y el desafío de desarrollar un pensamiento crítico o una conciencia histórica cuando existen problemas estructurales de comprensión de lectura. Este problema estructural tiene entre sus causas el Plan Decenal que permitió la graduación de maestros sin la formación necesaria, al paso que los futuros estudiantes de las universidades heredaban sus lagunas y fragilidades en Ciencias Sociales y Humanas (EDP10). Estas dificultades se agravan por los problemas económicos que impiden que muchos de los estudiantes accedan a las herramientas tecnológicas. En medio de la pandemia de COVID-19, como observa uno de los docentes, se desnudaron todas las brechas y fragilidades formativas de la educación pública dominicana.

Por otro lado, se destaca el desafío de avanzar en la homogenización de los niveles de formación de los docentes de Ciencias Sociales. Aunque existen avances en la transición hacia un modelo por competencias, el grueso de los docentes aún espera un mayor compromiso estatal con el fortalecimiento de sus capacidades en este ámbito. Para algunos, en la práctica, la transición curricular se dio sin que el docente estuviera capacitado para identificar la transversalidad de los temas analizados en este artículo, la manera como se insertan y las estrategias que ellos deben desarrollar para alcanzar los desafíos del cambio.

Es un desafío avanzar en debates académicos que permitan sensibilizar a los futuros estudiantes sobre los prejuicios y sus discursos, para que como ciudadanos críticos contribuyan a la construcción de una nueva sociedad dominicana. En este sentido, las universidades dominicanas deben afianzar y extender sus 
alianzas interinstitucionales, nacionales y extranjeras, para promover debates que enriquezcan el horizonte de análisis y reflexión sobre los problemas del país. Una apertura a nuevos temas y debates como los de la riqueza, la inequidad, la diversidad y el género, que además rompa con la tradición de los manuales que sigue vigente en las universidades (EDP6, EDP13). Sin embargo, esto no es posible mientras que los modelos de contratación y vinculación de los docentes no den garantías para la investigación y reflexión o la práctica docente esté de espaldas a la realidad dominicana y los horizontes teóricos que permitan analizarla (EDP13).

Antes de concluir, es importante plantear algunas reflexiones y observaciones acerca de los alcances y límites de la investigación. Los participantes coincidieron en que la formación del maestro de Ciencias Sociales y Humanas en el siglo XXI implica el desarrollo de las competencias de pensamiento lógico, crítico y creativo. Pero, sobre todo, destacan la importancia de profundizar en aspectos como identidades, ciudadanía, democracia, diversidad y género. Los entrevistados insisten tanto en la importancia de un enfoque "glocal" de los temas y un análisis de las Ciencias Sociales y Humanas, como en la defensa de una ciudadanía amplia y cosmopolita que permita reconocerse como parte de un todo. Así mismo, destacan el desarrollo de una conciencia ecológica, ambiental y social.

Ni las TIC ni los procesos de virtualización ocuparon un lugar central en el discurso de los docentes entrevistados, En futuras investigaciones cabría evaluar si esta opinión acerca de las transformaciones digitales en el ámbito educativo se transformó como resultado de la pandemia actual. De hecho, los docentes tenían la impresión de que la virtualidad era un proceso lento y gradual en países como República Dominicana, situación de la cual son ilustrativas las siguientes afirmaciones de la prensa local: "No estamos preparados para la virtualidad" (Diario Libre, 10 de julio de 2020), “¿Estamos preparados para la virtualidad?" (Listín Diario, 25 de mayo 2020), "El parto de la virtualidad" (Listín Diario, 20 de diciembre de 2020).
Nuestra hipótesis al comenzar la investigación era que el advenimiento de la CRI estaba impactando la profesión docente en República Dominicana o, por lo menos, suscitando algunas reflexiones entre los docentes de Ciencias Sociales y Humanas. Al finalizar, podemos concluir que los efectos de la transformación del trabajo o el lado negativo del proceso no es inminente en ninguno de los entrevistados, al menos explícitamente. A pesar de esto, implícitamente es posible percibir en un grupo minoritario cierta sensibilidad y conocimiento del tema, de allí que aludan a la formación de una ciudadanía glocal que permita la comprensión y acción sobre múltiples realidades sociales o la formación del pensamiento crítico, creativo y lógico.

Ahora bien, los límites, las dificultades, las incertidumbres e inequidades suscitadas por la transformación digital de las aulas no aparecen con claridad en el discurso de los entrevistados. Para la mayoría de ellos, así como para una parte importante de los autores que analizan el proceso, se trata de una cuestión asociada a las herramientas y a los recursos usados o de didáctica, por lo que lo conciben menos como un desafío social.

Aun así, cuando en las entrevistas los docentes dominicanos de Ciencias Sociales descentran los debates sobre el trabajo y las TIC para señalar que el desafío de la formación de los futuros docentes gira alrededor de las identidades, la democracia y la diversidad, lo hacen con plena conciencia de su entorno y su época. Es falso atribuir al contexto de la formación de docentes en República Dominicana las preocupaciones que se tejen en Davos. En República Dominicana y en Latinoamérica en general la concentración de la riqueza, el desempleo, la violencia de género, la discriminación, la corrupción y el populismo son problemas viejos de enorme actualidad, tanto porque los procesos de enseñanza y aprendizaje adquieren en el contexto global nuevos matices, como por el hecho de la reciente crisis, que hizo más palpable los desafíos de la educación en un mundo marcado por enormes inequidades. En una frase, todo docente latinoamericano sabe que la sociedad y la democracia están en 
“capilla ardiente" (EDP10), por eso insisten una y otra vez en la importancia de formar profesionales conscientes de estos problemas.

\section{Agradecimientos}

La investigación La enseñanza de las Ciencias Sociales y Humanas en el siglo XXI. El caso de República Dominicana, de la cual derivan los resultados presentados en este artículo, se realizó con recursos de la Convocatoria Interna de Investigación (2019) del Instituto Superior de Formación Docente Salomé Ureña (ISFODOSU).

\section{Referencias}

Aguilera, A. (2017). La enseñanza de la historia y las ciencias sociales hoy: Contrasentidos y posibilidades. Folios, 46, 15-27.

Aponte, J. E., Mendoza, N. C. \& Rodríguez, S. P. (2014). Movimientos, organizaciones sociales y acciones colectivas en la formación de profesores. Nómadas, 41, 167-183.

Appiah, A., Cohen, J. \& Nussbaum, M. C. (2016). Los limites del patriotismo: Identidad, pertenencia y "ciudadanía mundial". Paidós.

Arancibia H, M. \& Badia G, A. (2013). Caracterización y valoración de los usos educativos de las TIC en 10 secuencias didácticas de historia en enseñanza secundaria. Estudios pedagógicos (Valdivia), 39(Especial), 7-24. https://doi.org/ $10.4067 / \mathrm{s} 0718-07052013000300002$

Arias, D. H. (2015). La enseñanza de la historia reciente y la formación moral. Dilemas de un vínculo imprescindible. Folios, 42, 29-41.

Arias, D. H. (2017). Propósitos de la enseñanza de las ciencias sociales y la historia. Una aproximación desde relatos docentes. Aletheia. Revista de Desarrollo Humano, Educativo y Social Contemporáneo, 9(1), 18-37.

Atienza, E. \& Van Dijk, T. A. (2010). Identidad social e ideología en libros de texto españoles de Ciencias Sociales. http://repositorio.minedu.gob.pe/ handle/123456789/1205
Avelas, J. P. (2015). Historiographical research and the teaching of History. Thoughts in History didactics and the Learning Outcomes. Revista Portuguesa De Historia, 46, 487-507. https:// doi.org/10.14195/0870-4147_46_24

Balaguer, J. (1983). La isla al revés: Haití y el destino dominicano. Fundación José Antonio Caro.

Barbosa, M. V. \& Soares, O. P. (2017). Formar professores de ciências sociais: Uma necessidade histórica y social. Revista Eletronica Pesquiseduca, 9(18), 341-356.

Blanco, J. E. (2016). La enseñanza de las Ciencias Sociales en el contexto de la globalización y el Estado Social de Derecho. Amauta, 14(28), 171-187.

Büchi, S., \& Sensky, T. (1999). PRISM: Pictorial Representation of Illness and Self Measure. A brief nonverbal measure of illness impact and therapeutic aid in psychosomatic medicine. Psychosomatics, 40(4), 314-320. https://doi.org/ 10.1016/S0033-3182(99)71225-9

Bulcourf, P. A. (2008). Algunas reflexiones sobre la enseñanza de la ciencia política en la Argentina. Postdata, 13, 225-242.

Cabeza, I. (2012). La geografía escolar y las ciencias sociales: El caso de la secundaria oficial en España. Folios, 35, 87-105.

Cardozo, M. (2011). Las ciencias sociales y el problema de la complejidad. Argumentos (México, D.F.), 24(67), 15-35.

Carretero, M., Ruiz, C. \& Conchiña, J. (2015). Una enseñanza de las ciencias sociales para el futuro: Recursos para trabajar la invisibilidad de personas, lugares y temáticas. Universidad de Extremadura. https://dialnet.unirioja.es/servlet/libro?cod igo $=570009$

Carretero, M. \& Limón, M. (1993). Aportaciones de la psicología cognitiva y de la instrucción a la enseñanza de la Historia y las Ciencias sociales. Infancia y Aprendizaje, 16(62-63), 153-167. https://doi.org/10.1080/02103702.1993.108 22378 
Carretero, M. (2019). De noticias falsas, reconquistas y demás. Iber: Didáctica de las ciencias sociales, geografía e historia, 96, 55-61.

Carretero, M \& Sobrino, D. (2020). Fake news y pensamiento crítico. Editorial Graó. https:// www.grao.com/es/producto/fake-news-y-pensamiento-critico-ib10199361

Castells, M. (2015). Redes de indignación y esperanza: Los movimientos sociales en la era de internet. Alianza.

Castells, M. \& Hernández, M. (2014). Comunicación y poder. Alianza Editorial.

Castells, M., Martínez, C., Alborés, J. \& Lora, P. (2006). La era de la información: Economía, sociedad y cultura. Alianza Editorial.

Castillo, L. (20 de diciembre de 2020). El parto de la virtualidad. Listin Diario. https://r.issu.edu. $\mathrm{do} / 1$ ? $1=11331 \mathrm{ECd}$

Cerón, C. P. (2011). Europeos y no europeos en manuales escolares de geografía universal, Colombia 1970-1990. Revista Historia de la Educación Latinoamericana, 16, 57-86.

Cheah, K. (2020, julio 27). Managing Tensions between Theory and Practice: An Educator guide on Data Saturation with ATLAS.ti. ATLAS.ti. https:// atlasti.com/2020/07/27/managing-tensions-between-theory-and-practice-an-educator-guide-on-data-saturation-with-atlas-ti/

Cortina, A. (1998). Ciudadanos del mundo hacia una teoría de la ciudadanía. Alianza Editorial.

Cozar, R., Zagalaz, J., \& Saez, J. M. (2015). Creating digital curricular contents of Social Sciences for Primary Education. A TPACK experience for future teachers. Educatio Siglo Xxi, 33(3), 147-167. https://doi.org/10.6018/j/240921

Dipp, T. (1979). Raza e historia en Santo Domingo: Los orígenes del prejuicio racial en América. UASD.

Durán, C. (2019). Algunas reflexiones en torno a la enseñanza y aprendizaje de la Historia. Ecos, 1(17), 125-132.

Durand, J. P. (2011). La cadena invisible: Flujo tenso y servidumbre voluntaria. Fondo de Cultura Económica, Universidad Autónoma Metropolitana.
Espinoza, C., \& Mora, M. (2015). Construction of geographical knowledge and skills in higher education students. Uni-Pluriversidad, 15(1), 24-41.

Féliz, A. (2017). La Identidad Cultural Dominicana: Más allá de los discursos esencialistas. Perspectivas, 15(17), 2-12.

Flick, U. (2007). Introducción a la investigación cualitativa (2a ed.). Morata.

Foucault, M. (2004). Naissance de la biopolitique. Cours au Collège de France. 1978-1979. Seuil/ Gallimard.

Franco, F. J. (1979). Los negros, los mulatos y la Nación Dominicana. Editora Nacional. http://catalog. hathitrust.org/api/volumes/oclc/40835053.html

Fuertes, C. (2015). The teaching of history in higher education through oral sources. Didáctica De Las Ciencias Experimentales Y Sociales, 29, 135-155. https://doi.org/10.7203/DCES.29.3959

Fusch, P., \& Ness, L. R. (2015). Are We There Yet? Data Saturation in Qualitative Research. The Qualitative Report, 20(9), 1408-1416. https:// doi.org/null

García-Canclini, N. (1992). Culturas hibridas: Estrategias para entrar y salir de la modernidad. Sudamericana.

González, M. F. (2019). ¿Cómo se miran haitianos y dominicanos en los libros de texto escolares? Ecos, 1(17), 89-124.

González, R. (2010). Identidad dominicana: Política e historia. Clío, 179, 57-70.

Gorz, A. (1998). Miserias del presente, riqueza de lo posible. Galilée.

Gurdián, A. (2015). El paradigma cualitativo en la investigación socio-educativa (Reimpresión). Editorial UCR.

Guridi, V. \& Arriassecq, I. (2004). Historia y filosofía de las ciencias en la educación polimodal: Propuesta para su incorporación al aula. Ciência \& Educação (Bauru), 10(3), 307-316. https:// doi.org/10.1590/S1516-73132004000300001

Guzmán, F. (2017). Problemática general de la educación por competencias. Revista Iberoamericana De Educacion, 74(1), 107-120. 
Innerarity, D. (2020). Una teoría de la democracia compleja: Gobernar en el siglo XXI. Galaxia Gutenberg.

Iriarte, A. (2020). Los sistemas de educación superior en Latinoamérica: Tendencias, modalidades y estrategias en la actualidad (A. Mombru Ruggiero, Ed.). L.J.C.

Ishihara-Brito, R. \& Rodríguez, P. B. (2012). Reliquis, artefactos y herramientas educativas: Conservación del patrimonio. Chungará (Arica), 44(3), 445-453. https://doi.org/10.4067/S0717-735 62012000300007

Jaramillo, P. E. \& Ruiz, M. (2009). Un caso de integración de TIC que no agrega valor al aprendizaje. Revista Latinoamericana de Ciencias Sociales, Niñez y Juventud, 7(1), 267-287.

Laval, C. (2004). La escuela no es una empresa: El ataque neoliberal a la enseñanza pública. Paidós. Le Goff, J. P. (2009). La barbarie edulcorada. Siglo XXI. Mella, P. (2005). La identidad narrativa dominicana: Por un nuevo congreso extraparlamentario. Estudios Sociales, 41(142-143), 130-153.

Migueles, M. A., Auch, M., Corfield, M. I., Sattler, S., Tarulli, G., Viñas, F. \& Gobo, M. J. (2011). Las Didácticas en los profesorados... Especificidades que se construyen. Ciencia, docencia y tecnología, 43, 97-127.

Miles, M. B., Huberman, A. M., \& Saldaña, J. (2014). Qualitative data analysis: $A$ methods sourcebook ( $3^{\text {rd }}$ Edition). Sage.

Moreno-Fernández, O. (2018). La enseñanza de las Ciencias Sociales: Un diagnóstico a partir de las memorias, reflexiones y expectativas de profesores de enseñanza primaria en formación inicial. Ensaio: Avaliação e Políticas Públicas em Educação, 26(100), 1021-1037. https://doi. org/10.1590/s0104-40362018002601452

Morrillo, G. (25 de mayo de 2020). De las aulas a la virtualidad: Retos y desafios. Listín Diario. https://r.issu.edu.do/1?1=11330W6s

Muñoz, C. \& Martínez, R. (2015). Prácticas Pedagógicas y Competencias Ciudadanas: El Caso del Docente de Historia en Chile. Actualidades Investigativas en Educación, 15(3), 273-293.

Pantoja, P. T. (2017). Enseñar a enseñar Historia: La formación didáctica de los futuros profesores. Diálogo andino, 53, 59-71.

Pemjean, L. B. (2007). Enseńanza de la historia y las ciencias sociales y formación ciudadana: Bases para una propuesta de formación de profesores desde la didáctica de la especialidad. Las competencias profesionales para la enseñanza-aprendizaje de las ciencias sociales ante el reto europeo y la globalización (381-390). https://dialnet.uni rioja.es/servlet/articulo?codigo $=2568690$

Perrenoud, P. (2008). Construir competencias desde la escuela. JC Sáez.

Pink, S. \& Filella Roc. (2019). Etnografía digital: Principios y práctica.

Prats, J. (2006). Ensinar História no contexto das Ciências Sociais: Princípios básicos. Educar em Revista, Online(spe), 1-20. https://doi.org/10. 1590/0104-4060.406

Rakhimova, A. E., Yashina, M. E., Mukhamadiarova, A. F., \& Sharipova, A. V. (2017). The Development of Sociocultural Competence with the Help of Computer Technology. Interchange, 48(1), 55-70. https://doi.org/10.1007/s10780016-9279-5

Ríos, S. M. \& Ramos, J. C. (2011). Implicaciones de la teoría piagetiana en la enseńanza de las Ciencias Sociales. Revista Colombiana de Educación, 60, 61-70.

Rodríguez Ávila, S. P. \& Acosta Jiménez, W. A. (2007). La emergencia de la didáctica de las ciencias sociales: ¿campo en consolidación o en disgregación? Folios, 25, 37-52.

Román-Calderón, J. P., Gonzáles-Miranda, D., Gallo, Ó., \& García, G. (2020). Using PRISM to test amotivation as a mediator between workhome and turnover. TPMTesting, Psychometrics, Methodology in Applied Psychology, 27, 171-184.

Rosanvallon, P. (2010). La legitimidad democrática: Imparcialidad, reflexividad y proximidad. Paidós.

Rosario, R. (2019). La formación docente y la enseńanza de la Historia. Ecos, 1(17), 134-172. 
Rubbi, L. N., Barlaro Rovati, B., Petraglia, A., Rubbi, L. N., Barlaro Rovati, B. \& Petraglia, A. (2020). ¿Perdidos o salvados? El futuro del trabajo frente a la cuarta Revolución Industrial. Desde el Sur, 12(1), 307-342. https://doi.org/10.21142/des1201-2020-0018

Ryder, G. (2017). El futuro del trabajo que queremos: Un diálogo global. Organización Internacional del Trabajo.

Saunders, B., Sim, J., Kingstone, T., Baker, S., Waterfield, J., Bartlam, B., Burroughs, H., \& Jinks, C. (2018). Saturation in qualitative research: Exploring its conceptualization and operationalization. Quality \& Quantity, 52(4), 1893-1907. https://doi.org/10.1007/s11135-017-0574-8

Schwab, K. (2016). The Fourth Industrial Revolution. World Economic Forum.

Sensky, T., \& Büchi, S. (2016). PRISM, a Novel Visual Metaphor Measuring Personally Salient Appraisals, Attitudes and Decision-Making: Qualitative Evidence Synthesis. PLOS ONE, 11(5), e0156284. https://doi.org/10.1371/ journal.pone. 0156284

Soaje-de Elias, R. (2012). Estudio de los textos de Historia y de Ciencias Sociales chilenos entre 2000 y 2010. Educación y Educadores, 15(1), $23-41$.
Solórzano, M. del C. \& Valverde, K. (2008). Estrategias de enseñanza en ciencias sociales: Una aproximación desde la experiencia docente. UNAM, Facultad de Ciencias Políticas y Sociales: Gernika.

Suero, I. (10 de julio de 2020). Roberto Fulcar dice que el país aún no está listo para impartir clases virtuales. Diario Libre. https://r.issu.edu. do/1? $1=11329 \mathrm{cX} 3$

Toledo, M. I., Magendzo, A., Gutiérrez, V. \& Iglesias, R. (2015). Enseñanza de "temas controversiales" en la asignatura de historia y ciencias sociales desde la perspectiva de los profesores. Estudios pedagógicos (Valdivia), 41(1), 275-292. https:// doi.org/10.4067/S0718-07052015000100016

Vila, R. (2019). Consecuencias económicas y sociales de la cuarta revolución industrial y estrategias pensadas para la adaptación de la actividad económica. Revista Aportes de la Comunicación y la Cultura, 26, 89-108.

Weiner, M. F. (2015). Whitening a diverse Dutch classroom: White cultural discourses in an Amsterdam primary school. Ethnic and Racial Studies, 38(2), 359-376. https://doi.org/10.10 80/01419870.2014.894200

Wineburg, S. (2018). Why Learn History (When It's Already on Your Phone). University of Chicago Press. 
